Sarah Bauer ORCID iD: 0000-0003-4023-7048

Clement Ren ORCID iD: 0000-0003-4431-0644

A. Ioana Cristea ORCID iD: 0000-0002-9206-2190

Title

\title{
Nutrition and Growth in Infants with Established Bronchopulmonary Dysplasia
}

\author{
Sarah E. Bauer, $\mathrm{MD}^{1}$, Charles P.B. Vanderpool, $\mathrm{MD}^{1}$, Clement Ren, $\mathrm{MD}^{2}$, A. Ioana \\ Cristea, MD, MS ${ }^{1}$ \\ ${ }^{1}$ Pediatrics, Indiana University, Indianapolis, IN, United States \\ 2 \\ Division of Pulmonary and Sleep Medicine, Children's Hospital of Philadelphia, \\ Philadelphia, PA, United States
}

\section{Address correspondence to:}

\author{
A. Ioana Cristea, MD, MS \\ Division of Pediatric Pulmonology, Allergy, and Sleep Medicine \\ Riley Hospital for Children \\ 705 Riley Hospital Drive \\ Indianapolis, IN. 46202 \\ Email: aicriste@iu.edu
}

KEY WORDS: enteral nutrition, feeding, oxygen, parenteral nutrition, prematurity

Funding: No funding was received for this study.

Conflict of Interest/Disclosures: The authors have no conflict of interest to disclose.

Abbreviations: breast milk (BM), bronchopulmonary dysplasia (BPD), gastroesophageal reflux disease (GERD), parenteral nutrition (PN), nasogastric tubes (NG), necrotizing enterocolitis (NEC), neonatal intensive care unit (NICU), transcutaneous gastrostomy tube (GT)

This is the author's manuscript of the article published in final edited form as:

Bauer, S. E., Vanderpool, C. P. B., Ren, C., \& Cristea, A. I. (2021). Nutrition and Growth in Infants with Established Bronchopulmonary Dysplasia. Pediatric Pulmonology, 56(11), 3557-3562. https://doi.org/10.1002/ppul.25638 
Abbreviated Title: Established BPD, Growth, and Nutrition

\begin{abstract}
Bronchopulmonary dysplasia (BPD) remains the most common late morbidity of preterm birth. Ongoing clinical care and research have largely focused on the pathogenesis and prevention of BPD in preterm infants. However, preterm infants who develop BPD have significant medical needs that persist throughout their neonatal intensive care unit course and continue post-discharge, including those associated with growth and nutrition. The objective of this manuscript was to provide a review on nutrition and growth in infants with established BPD after discharge from the hospital and to identify the knowledge and research gaps to provide direction for future studies.
\end{abstract}

\title{
Introduction
}

Nutrition plays a critical role in respiratory development of infants with bronchopulmonary dysplasia (BPD), whose saccular-alveolar stage of lung maturation occurs mostly or entirely in post-natal life. ${ }^{1,2}$ Infants with BPD have increased caloric needs, which continue after discharge from the hospital. These nutritional needs are often unmet, as evidenced by data showing that infants and young children with BPD are smaller than term controls, with greater deficits observed in weight than in height, and growth abnormalities might persist into adolescence and adulthood..$^{3-5}$ Growth delay is also associated with severe and prolonged respiratory dysfunction, and nutritional status in former infants with BPD at 2 years of age is a predictor of pulmonary function later in childhood. ${ }^{6}$ Conversely, improvement in respiratory symptoms is associated with an accelerated growth rate. ${ }^{4}$ These data highlight the importance of growth and nutrition in affecting pulmonary outcomes in BPD. In this article, we will review the epidemiology of nutritional deficits in BPD, the mechanisms by which growth failure contributes to worse lung

This article is protected by copyright. All rights reserved. 
function, factors contributing to poor nutrition in BPD, and suggestions for nutritional management in BPD.

\section{Epidemiology of nutrition in BPD}

In the neonatal period, infants born preterm have greater nutritional needs to match the high rates of weight gain achieved by infants in utero. The Eunice Kennedy Shriver National Institute of Child Health and Human Development (NICHD) Growth Observational Study ${ }^{7}$ demonstrated that, although the rate of weight gain was similar to the reported intrauterine rate of weight gain ( $15 \mathrm{~g} / \mathrm{kg}$ per day), once birth weight was regained, most of the infants born at a gestational age between 24 to 29 weeks did not achieve the median birth weight of the reference fetus of the same post-menstrual age (PMA) at hospital discharge. In fact, at discharge from the neonatal intensive care unit (NICU) or at 36 weeks' PMA, most were less than the comparable 10th percentile birth weight for completed weeks of gestation. ${ }^{8}$ Table 1 provides a summary of NICU morbidities and other factors associated with higher incidence of postnatal growth failure. ${ }^{9}$

Energy needs for an infant with BPD have been estimated to be $15 \%$ to $25 \%$ greater than for an infant without BPD, and thus, in the range of 140 to $150 \mathrm{kcal} / \mathrm{kg} / \mathrm{day} .{ }^{10}$ Often, increased calorie and protein delivery is required to meet the increased energy expenditures and metabolic needs of these vulnerable infants. ${ }^{11}$ In addition, patients born prematurely may lack the ability to feed orally. The occurrence of gagging, choking, and vomiting, and other issues related to oro-motor coordination can contribute to the suboptimal nutrition of these patients. Increased metabolic demands can also cause growth failure. ${ }^{12}$ Developmental delays, lower social economic status, tobacco smoke exposure, indoor air pollution can have further impact on growth and respiratory outcomes of patients with BPD. ${ }^{13-15}$

This article is protected by copyright. All rights reserved. 


\section{Pathophysiology}

The effects of post-natal undernutrition on lung maturation have been characterized in animal models. Rodent models, which are at a saccular stage of lung development when born at term ${ }^{2}$, suggest that early post-natal undernutrition affects the bronchiolar epithelium ${ }^{16}$ and disrupts alveolarization ${ }^{17}$, with a reduction of both epithelial cells division and conversion of club cells to ciliated cells. Lamb models have demonstrated that fetal growth restriction can induce changes to both the chest wall and lung which persistent and subsequently impair respiratory function early in life. ${ }^{18}$ Furthermore, post-natal growth restriction has been shown to augment oxygeninduced pulmonary hypertension in rat models. ${ }^{19}$ Additional studies have found that alveolar formation is dysregulated by restricted nutrition ${ }^{20}$ and malnutrition can reduce lung weight, lung weight-to-birth-weight ratio, lung volumes, as well as the number of alveoli and elastic fibers and collagen deposition. ${ }^{21}$

Clinical studies have reported that infants with BPD have increased energy expenditure compared to preterm infants without BPD. ${ }^{22-24}$ Total daily energy expenditure has been found to be $16 \%$ greater in infants with BPD comparted to match controls. ${ }^{24}$ This is likely due to increased work of breathing, increased respiratory rate, and increased FiO2 requirement. ${ }^{24-26} \mathrm{De}$ Meer et al. found that infants with BPD require an additional $7.5 \mathrm{kcal} / \mathrm{kg} /$ day of energy intake for every additional 10 breaths/min greater than 60 breaths $/ \mathrm{min} .{ }^{25}$ Additional contributing factors for increased energy expenditure include growth suppression from chronic stress and inflammation, ${ }^{27}$ and chronic corticosteroid and/or diuretic use. Research has shown that infants with BPD who have received dexamethasone therapy have decreased weight gain, head circumference, length, and skinfold thickness during therapy. ${ }^{28}$ However, at term and three months corrected age, there was no difference compared to controls.

This article is protected by copyright. All rights reserved. 
Several studies have also demonstrated postnatal growth restriction in preterm infants, particularly in those with BPD, suggesting that these increased energy needs can have an impact on long term growth. ${ }^{7,29,30}$ It has been shown that by 2-4 weeks of age, infants with BPD have lower weight, length, and head circumference z-scores, as well as arm muscle area and arm fat area measurements, compared to infants without BPD matched for gestational age and birth weight. ${ }^{29}$ Another study demonstrated that infants with BPD at 12 months post-term age, compared to healthy term infants, had a significantly lower weight, length, fat free mass, and total body fat, despite having energy and protein intake at or above the recommended daily intake for healthy term infants during the first six months. ${ }^{30}$

Other factors that may contribute to growth retardation in BPD include intrauterine growth restriction, which is a risk factor for $\mathrm{BPD}$, and NEC. ${ }^{31,32} \mathrm{~A}$ history of NEC is associated with slower growth rates and growth delay. ${ }^{33,34}$ Treatment of NEC can require bowel resection, potentially leading to short gut syndrome or other problems of gastrointestinal absorption. While there have been no studies directly assessing the impact of NEC on growth in BPD, it is likely that NEC can contribute to poor growth in this patient population In summary, animal models provide a mechanistic rationale for the impact of nutrition on lung growth and development, and clinical data demonstrate that infants with BPD have increased caloric needs. An inability to meet these increased needs can result in growth failure and worse pulmonary outcomes.

\section{Dietary Factors}

Formula Selection

The nutritional support of infants and children with established BPD is focused on provision of appropriate calories to promote growth and avoid growth failure. To that end, nutritional support in BPD is similar to that provided to premature infants without lung disease. There is

This article is protected by copyright. All rights reserved. 
limited and mixed data describing optimal oral or enteral nutrition in the setting of BPD; experimental design and formula/feeding choice vary between study and outcomes described also vary. The American Academy of Pediatrics (AAP) recommends ${ }^{35}$ that mother's breast milk should be used through the first 6 months of life. Data suggests that use of breast milk may be associated with reduced emergency department visits and need for systemic steroids in young children with $\mathrm{BPD},{ }^{36}$ while data on reduction in hospitalization for lower respiratory tract infection is mixed. ${ }^{37}$ Recent data has suggested that exclusive breastfeeding in infants may be associated with lower oxygen need in BPD infants following initial discharge. ${ }^{38}$ Adequate protein intake is necessary to promote linear growth, lung growth, and repair of damaged tissue. ${ }^{39}$ However, at present, there are no specific protein intake recommendations for infants with BPD. The AAP recommends 3.2 to $4.5 \mathrm{~g} / \mathrm{kg} / \mathrm{d}$ of enteral protein for preterm infants. ${ }^{40}$ Although excessive calories may increase $\mathrm{CO} 2$ production, the net caloric gain from higher protein intake improves growth of infants with BPD.

Following cessation of breast milk consumption, the selection of a specific infant formula is based on patient gestational age, postnatal age, and nutritional needs. Studies on the use of a fortified discharge formula have demonstrated improved length, lean mass, and bone mass. ${ }^{10,41}$,

${ }^{42}$ However, there is insufficient data to support the selection of a specific formula in infants with established BPD.

Role of Calorie Supplementation Infants with established BPD may require caloric supplementation to avoid growth failure due to prematurity and an increase in total energy expenditure. Various caloric supplementation strategies have been investigated in the setting of BPD but definite evidence-based guidelines cannot be developed based on available evidence. After confirming appropriate protein delivery, caloric supplementation should focus on providing sufficient nonprotein calories to

This article is protected by copyright. All rights reserved. 
promote appropriate weight gain and linear growth. It is common for infants with established BPD to require caloric supplementation (many require 22 to 30 calories per ounce (cal/oz) formulas or fortified BM).

Ready-to-feed toddler formulas are available with a standard 30cal/oz concentration. However, these formulas are more appropriate for children greater than 1 year of age. In infants, if concentration of infant formula to $30 \mathrm{cal} / \mathrm{oz}$ is needed, attention should be given to how the formula caloric density is achieved. Infant formula caloric supplementation may be achieved with use of glucose or fat sources. Fat (compared to glucose) provides a concentrated energy source and has a lower respiratory quotient and thus a lower production of carbon dioxide. ${ }^{43}$. Use of a high-fat infant formula was associated with lower carbon dioxide formula in one study, but the impact on growth was mixed. Adequate growth was seen with the high fat formula, but higher weight gain was seen with higher carbohydrate intake ${ }^{44}$. While evidence is limited regarding optimal strategy of caloric supplementation, clinicians should be aware of the nuances regarding fat and glucose supplementation especially during caloric concentration of infant formula. Consultation with a dietitian who is knowledgeable and experienced in the care of preterm infants and children can be helpful. ${ }^{39}$

Other Dietary Factors

Micronutrients and Vitamins

There is limited evidence with regards to use of specific micronutrient supplementation during nutritional management of infants with established BPD. Zinc is an essential micronutrient that is involved in multiple cellular processes including growth, tissue repair, carbohydrate tolerance, and the host immune response and healing. Zinc supplementation should be considered in infants with BPD and poor growth ${ }^{45}$, especially if other symptoms of zinc deficiency are present including diarrhea or acro-orifical rash. The role of Vitamin A has been examined as an

This article is protected by copyright. All rights reserved. 
intervention to prevent BPD, however, it's nutritional value for patients with established BPD is not known. On the whole, there is no evidence to suggest that specific vitamin supplementation above recommended dietary intake has a role in treatment or management of infants with established BPD.

Parenteral Nutrition

Parenteral nutrition (PN) is typically a key component of early nutritional management in infants at risk for BPD. Continued need for PN in infants with established BPD may coincide with a diagnosis of short bowel syndrome or intestinal failure. Similar to formula concentration, provision of PN in the patient with BPD should be focused on delivery of protein to meet needs. Appropriate dosing and choice of PN lipid should allow for avoidance of glucose infusion above standard glucose infusion rates for age ${ }^{46}$. PN Lipid restriction in the infant with BPD, and subsequent excess glucose infusion, should be avoided if possible due to risk of $\mathrm{CO} 2$ production.

\section{Other Contributing Factors}

There are many other contributing factors which affect growth and nutrition in patients with BPD. Swallowing dysfunction is common in this population and likely contributes to chronic respiratory symptoms in children with BPD. ${ }^{47}$ Lung disease has been shown to be a major independent determinant of delayed feeding skills and time to full oral feeds in premature infants born before 32 weeks gestation. ${ }^{48}$ One study identified that infants with BPD had higher respiratory rates, more oxygen desaturations, and poor suck-swallow-breath coordination, as well as poor sucking endurance and performance compared to preterm infants without BPD while oral feeding. ${ }^{49}$ The same study also identified that feeding problems were dependent on the severity of BPD, with infants with severe BPD having worse feeding efficiency. ${ }^{49}$ Similar results have been reported by Wang et al who demonstrated significantly lower mean oxygen saturation levels during feeding at 2-6 months corrected age in very low birth weight infants

This article is protected by copyright. All rights reserved. 
with severe BPD compared to very low birth weight infants with mild BPD and term infants. Additionally, throughout the study period infants with severe BPD had higher rates of growth delay defined as weight less than the $10^{\text {th }}$ percentile..$^{50}$

Once an infant is able to tolerate oral feeds, evaluation for aspiration (by an experienced occupational or speech therapist with further diagnostics tests if warranted) is needed to assure intact swallow mechanisms. If swallowing dysfunction is identified, often the next step is to explore alternative routes of enteral feeding such as nasogastric tubes (NG) or transcutaneous gastrostomy tubes (GTs). GT placement is common in preterm infants and low birthweight infants, particularly in infants with BPD. ${ }^{51}$ However, the frequency and timing of surgical intervention, such as GTs and/or Nissen fundoplication (if gastro-esophageal reflux is identified), varies widely by site and clinical practice. McGrath-Morrow et al. examined the association of the presence of a GT or Nissen/GT and respiratory outcomes of children with BPD in the first 2 years of life and found that compared to those without GTs, both children with GTs and children with Nissen/GTs took longer to wean off supplemental oxygen. ${ }^{47}$ In the same study, there was no significant difference in reported respiratory morbidities among the three groups. However, children with Nissen/GTs did have higher re-hospitalizations after initial discharge. ${ }^{47}$ Similar findings of increased hospital admissions in patients with GTs for the treatment of aspiration compared to patients with aspiration fed orally have been reported by McSweeney et al. Notably, however, their study was not restricted to only patients with BPD. ${ }^{52}$ In both of these studies, it was not possible to determine if GTs contributed to respiratory morbidity or were simply a marker for more severe disease.

In addition to swallowing dysfunction, feeding can also be impaired by oral aversion, feeding intolerance, and gastroesophageal reflux disease (GERD) which subsequently may contribute to worsening lung disease and impaired growth. ${ }^{47,49,53}$

This article is protected by copyright. All rights reserved. 
As noted above, poor growth can impact lung development. Conversely, lung disease can impact poor growth. Duration of ventilator therapy has been found to be a risk factor for poor growth in very low birth weight infants with BPD. ${ }^{54}$ Furthermore, pulmonary function testing in childhood has shown correlation between airway obstruction and body composition. Studies have shown children with BPD and airway obstruction have lower fat mass and lower free-fat mass compared to controls. 6,55

The multifactorial etiologies of feeding and swallowing dysfunction in this population emphasizes the importance of an interdisciplinary team approach to feeding in both the inpatient and outpatient setting for patients with BPD. ${ }^{56,57}$ Additionally, more research is needed to evaluate best approaches to the work-up and management of feeding in this population.

\section{Approach to Nutritional Management of Infants and Children with BPD}

In spite of the increased number of patients with BPD, there is scarce evidence addressing how to optimize nutrition in patients with established BPD. Frequent assessments are critical to maintain optimal nutrition and growth in these patients. ${ }^{11}$ Close monitoring of nutritional status and growth is important not only to ensure an adequate growth trajectory but also to monitor for excess in weight gain due to intensive nutritional support. Excess weight gain in early infancy may increase the risk of insulin resistance and adult onset metabolic disease. ${ }^{58,59}$

Optimal growth is essential for the infant with BPD to be successfully weaned from oxygen and to continue the delayed alveolarization that can occur during childhood. One of the criteria for weaning oxygen is adequate growth and weight gain (goal of 20 to 30 grams per day). ${ }^{60}$ Although breastfeeding is encouraged, many of these infants will require additional fortified breastmilk or formula to maintain adequate caloric intake and mineral supplementation. Along with additional calories, maintaining adequate micronutrients and vitamins is essential for

This article is protected by copyright. All rights reserved. 
adequate lung growth. ${ }^{39,61}$ As respiratory symptoms improve and growth velocity is maintained off oxygen, caloric intake is often weaned around 1 year of life. Some children with severe BPD will require additional calorie drinks (Pediasure, Carnation Instant Breakfast) into early childhood to maintain adequate growth.

Nutritional management in BPD can benefit from an interdisciplinary team approach that includes pulmonologists, gastroenterologist, dietitians, and speech pathologists. At every followup visit, nutritional history should be obtained including type and frequency of feeding, nutritional supplements, food allergy or intolerance, chewing and swallowing problems, vomiting, diarrhea or constipation, gagging, choking or gastroesophageal reflux, behavioral problems related to eating, and current and past medications. ${ }^{62}$ Body measurements (weight, length, and head circumference) should be obtained at every follow up visit and plotted on appropriate growth charts. Blood tests can help in further assessment of nutritional status. Electrolytes should be monitored if the patient is receiving diuretics. Liver function tests are necessary to assess parenteral nutrition related cholestasis. Other mineral levels (calcium, phosphorus, magnesium, and alkaline phosphate) may indicate ongoing metabolic bone disease. If an iron deficiency is suspected, complete blood count and serum ferritin levels may be obtained. Albumin and prealbumin levels can aid in assessing energy and protein intake over a longer period of time. Specific vitamins, including vitamin A, and minerals, including zinc and selenium, can be determined if deficiency is suspected. The nutritional plan for infants should be individualized before discharge and should be reviewed regularly by a nutritionist with specific training and skills in the management of patients with established BPD.

The early recognition and management of swallowing dysfunction, oral aversion, and gastroesophageal reflux is essential to ensure feeding adequacy. Follow up by a pediatric gastroenterologist is recommended for infants with associated gastrointestinal problems, such

This article is protected by copyright. All rights reserved. 
as GERD, short gut syndrome, or intestinal motility disorders. Chronological age may not be a good predictor for initiation of solid food as infants with BPD may achieve these developmental skills later due to prolonged hospitalization. Foods with thicker consistency may be swallowed more easily. If there is food aversion or respiratory compromise, a speech pathologist or occupational therapist should be consulted for supervised feeding. Oro-motor stimulation should be initiated early on for infants needing prolonged tube feeds. Some feeding problems may be related to psychosocial issues and referral to behavioral psychologist may be required.

\section{Summary}

Growth and nutrition play a key role in long-term pulmonary outcomes in infants with BPD, and the multiple factors can contribute to growth failure in this group of patients. Frequent monitoring and an aggressive approach to growth failure, feeding problems, and inadequate nutrition should be essential elements of the care of infants with BPD, and an interdisciplinary approach will help achieve optimal outcomes. ${ }^{39}$ Despite the importance of nutrition in BPD, there is a paucity of high quality evidence to help guide selection of feeding regimens or use of interventions such at GTs that will result in optimal nutritional outcomes in BPD. While randomized controlled trials may be unethical or impractical, well-designed prospective cohort studies may identify practices associated with better nutritional outcomes, and these studies are urgently needed.

\section{References:}

1. Briana, D. D.; Malamitsi-Puchner, A., Small for gestational age birth weight: impact on lung structure and function. Paediatr. Respir. Rev. 2013, 14 (4), 256-262.

2. Joss-Moore, L. A.; Lane, R. H.; Albertine, K. H., Epigenetic contributions to the developmental origins of adult lung disease. Biochem. Cell Biol. 2015, 93 (2), 119-127.

This article is protected by copyright. All rights reserved. 
3. Northway, W. H., Jr.; Moss, R. B.; Carlisle, K. B.; Parker, B. R.; Popp, R. L.; Pitlick, P. T.; Eichler, I.; Lamm, R. L.; Brown, B. W., Jr., Late pulmonary sequelae of bronchopulmonary dysplasia. N. Engl. J. Med. 1990, 323 (26), 1793-9.

4. Markestad, T.; Fitzhardinge, P. M., Growth and development in children recovering from bronchopulmonary dysplasia. J. Pediatr. 1981, 98 (4), 597-602.

5. Yu, V. Y.; Orgill, A. A.; Lim, S. B.; Bajuk, B.; Astbury, J., Growth and development of very low birthweight infants recovering from bronchopulmonary dysplasia. Arch. Dis. Child. 1983, 58 (10), 791-4.

6. Bott, L.; Béghin, L.; Devos, P.; Pierrat, V.; Matran, R.; Gottrand, F., Nutritional status at 2 years in former infants with bronchopulmonary dysplasia influences nutrition and pulmonary outcomes during childhood. Pediatr. Res. 2006, 60 (3), 340-344.

7. Ehrenkranz, R. A.; Younes, N.; Lemons, J. A.; Fanaroff, A. A.; Donovan, E. F.; Wright, L. L.; Katsikiotis, V.; Tyson, J. E.; Oh, W.; Shankaran, S., Longitudinal growth of hospitalized very low birth weight infants. Pediatrics 1999, 104 (2), 280-289.

8. Alexander, G.; Himes, J.; Kaufman, R.; Mor, J.; Kogan, M., A United States national reference for fetal growth Obstet Gynecol 87: 163-168. Find this article online 1996.

9. Clark, R. H.; Thomas, P.; Peabody, J., Extrauterine growth restriction remains a serious problem in prematurely born neonates. Pediatrics 2003, 111 (5), 986-990.

10. Carlson, S. J., Current nutrition management of infants with chronic lung disease. Nutr. Clin. Pract. 2004, 19 (6), 581-586.

11. Groothuis, J. R.; Makari, D., Definition and outpatient management of the very low-birth-weight infant with bronchopulmonary dysplasia. Adv. Ther. 2012, 29 (4), 297311.

12. Kurzner, S. I.; Garg, M.; Bautista, D. B.; Bader, D.; Merritt, R. J.; Warburton, D.; Keens, T. G., Growth failure in infants with bronchopulmonary dysplasia: Nutrition and elevated resting metabolic expenditure. Pediatrics 1988, 81 (3), 379-384.

13. Johnson, D. B.; Cheney, C.; Monsen, E. R., Nutrition and feeding in infants with bronchopulmonary dysplasia after initial hospital discharge: risk factors for growth failure. J. Am. Diet. Assoc. 1998, 98 (6), 649-656.

14. Collaco, J. M.; Aherrera, A. D.; Ryan, T.; McGrath-Morrow, S. A., Secondhand smoke exposure in preterm infants with bronchopulmonary dysplasia. Pediatr. Pulmonol. 2014, 49 (2), 173-178.

This article is protected by copyright. All rights reserved. 
15. Rice, J. L.; McGrath-Morrow, S. A.; Collaco, J. M., Indoor air pollution sources and respiratory symptoms in Bronchopulmonary dysplasia. The Journal of pediatrics 2020, 222, 85-90. e2.

16. Massaro, G. D.; McCoy, L.; Massaro, D., Postnatal undernutrition slows development of bronchiolar epithelium in rats. American Journal of PhysiologyRegulatory, Integrative and Comparative Physiology 1988, 255 (4), R521-R526.

17. Gaultier, C., Malnutrition and lung growth. Pediatr. Pulmonol. 1991, 10 (4), 278286.

18. Joyce, B. J.; Louey, S.; Davey, M. G.; Cock, M. L.; Hooper, S. B.; Harding, R., Compromised respiratory function in postnatal lambs after placental insufficiency and intrauterine growth restriction. Pediatr. Res. 2001, 50 (5), 641-649.

19. Wedgwood, S.; Warford, C.; Agvateesiri, S. C.; Thai, P.; Berkelhamer, S. K.; Perez, M.; Underwood, M. A.; Steinhorn, R. H., Postnatal growth restriction augments oxygeninduced pulmonary hypertension in a neonatal rat model of bronchopulmonary dysplasia. Pediatr. Res. 2016, 80 (6), 894-902.

20. Joss-Moore, L. A.; Hagen-Lillevik, S. J.; Yost, C.; Jewell, J.; Wilkinson, R. D.; Bowen, S.; Dahl, M. J.; Dong, L.; Wang, Z.; Presson, A. P., Alveolar formation is dysregulated by restricted nutrition but not excess sedation in preterm lambs managed by noninvasive support. Pediatr. Res. 2016, 80 (5), 719-728.

21. Mataloun, M.; Leone, C.; Mascaretti, R.; Dohlnikoff, M.; Rebello, C., Effect of postnatal malnutrition on hyperoxia-induced newborn lung development. Braz. J. Med. Biol. Res. 2009, 42 (7), 606-613.

22. Denne, S. C., Energy expenditure in infants with pulmonary insufficiency: is there evidence for increased energy needs? The Journal of nutrition 2001, 131 (3), 935S-937S.

23. Yeh, T. F.; McClenan, D. A.; Ajayi, O. A.; Pildes, R. S., Metabolic rate and energy balance in infants with bronchopulmonary dysplasia. J. Pediatr. 1989, 114 (3), 448-451.

24. De Meer, K.; Westerterp, K. R.; Houwen, R. H. J.; Brouwers, H. A. A.; Berger, R.; Okken, A., Total energy expenditure in infants with bronchopulmonary dysplasia is associated with respiratory status. Eur. J. Pediatr. 1997, 156 (4), 299-304.

25. de Meer, K.; Westerterp, K. R.; Houwen, R. H.; Brouwers, H. A.; Berger, R.; Okken, A., Total energy expenditure in infants with bronchopulmonary dysplasia is associated with respiratory status. Eur. J. Pediatr. 1997, 156 (4), 299-304.

26. Andrews, J.; Guyatt, G.; Oxman, A. D.; Alderson, P.; Dahm, P.; Falck-Ytter, Y.; Nasser, M.; Meerpohl, J.; Post, P. N.; Kunz, R.; Brozek, J.; Vist, G.; Rind, D.; Akl, E. A.; Schunemann, H. J., GRADE guidelines: 14 . Going from evidence to recommendations:

This article is protected by copyright. All rights reserved. 
the significance and presentation of recommendations. J. Clin. Epidemiol. 2013, 66 (7), 719-25.

27. Balinotti, J. E.; Chakr, V. C.; Tiller, C.; Kimmel, R.; Coates, C.; Kisling, J.; Yu, Z.; Nguyen, J.; Tepper, R. S., Growth of lung parenchyma in infants and toddlers with chronic lung disease of infancy. Am. J. Respir. Crit. Care Med. 2010, 181 (10), 1093-1097.

28. Bolt, R. J.; van Weissenbruch, M. M.; Roos, J. C.; Delemarre-van de Waal, H. A.; Cranendonk, A.; Lafeber, H. N., Body composition in infants with chronic lung disease after treatment with dexamethasone. Acta Paediatr. 2002, 91 (7), 815-21.

29. DeRegnier, R. A. O.; Guilbert, T. W.; Mills, M. M.; Georgieff, M. K., Growth failure and altered body composition are established by one month of age in infants with bronchopulmonary dysplasia. J. Nutr. 1996, 126 (1), 168-175.

30. Huysman, W. A.; de Ridder, M.; de Bruin, N. C.; van Helmond, G.; Terpstra, N.; Van Goudoever, J. B.; Sauer, P. J., Growth and body composition in preterm infants with bronchopulmonary dysplasia. Archives of Disease in Childhood Fetal \& Neonatal Edition 2003, 88 (1), F46-51.

31. Groene, S. G.; Spekman, J. A.; te Pas, A. B.; Heijmans, B. T.; Haak, M. C.; van Klink, J. M.; Roest, A. A.; Lopriore, E., Respiratory distress syndrome and bronchopulmonary dysplasia after fetal growth restriction: Lessons from a natural experiment in identical twins. EClinicalMedicine 2021, 32, 100725.

32. McGrath-Morrow, S. A.; Collaco, J. M., Bronchopulmonary dysplasia: what are its links to COPD? Ther. Adv. Respir. Dis. 2019, 13, 1753466619892492.

33. Hintz, S. R.; Kendrick, D. E.; Stoll, B. J.; Vohr, B. R.; Fanaroff, A. A.; Donovan, E. F.; Poole, K. W.; Blakely, M. L.; Wright, L.; Higgins, R., Neurodevelopmental and growth outcomes of extremely low birth weight infants after necrotizing enterocolitis. Pediatrics 2005, $115(3), 696-703$.

34. Malek, A. J.; Mrdutt, M. M.; Scrushy, M. G.; Mallet, L. H.; Shaver, C. N.; Sanders, E. C.; Stagg, H. W.; Perger, L., Long-term growth outcomes in neonates diagnosed with necrotizing enterocolitis: a 20-year analysis. J. Pediatr. Surg. 2019, 54 (5), 949-954.

35. Eidelman, A. I., Breastfeeding and the use of human milk: an analysis of the American Academy of Pediatrics 2012 Breastfeeding Policy Statement. Breastfeed. Med. 2012, 7 (5), 323-324.

36. Kim, L. Y.; McGrath-Morrow, S. A.; Collaco, J. M., Impact of breast milk on respiratory outcomes in infants with bronchopulmonary dysplasia. Pediatr. Pulmonol. 2019, 54 (3), 313-318.

This article is protected by copyright. All rights reserved. 
37. Acuña-Cordero, R.; Sossa-Briceño, M. P.; Rodríguez-Martínez, C. E., Predictors of hospitalization for acute lower respiratory infections during the first two years of life in a population of preterm infants with bronchopulmonary dysplasia. Early Hum. Dev. 2018, 127, 53-57.

38. Montealegre, A.; Charpak, N., Anemia, nutrition and ambulatory oxygen weaning in a cohort of oxygen-dependent premature infants. Authorea Preprints 2020.

39. Abman, S. H.; Collaco, J. M.; Shepherd, E. G.; Keszler, M.; Cuevas-Guaman, M.; Welty, S. E.; Truog, W. E.; McGrath-Morrow, S. A.; Moore, P. E.; Rhein, L. M.; Kirpalani, H.; Zhang, H.; Gratny, L. L.; Lynch, S. K.; Curtiss, J.; Stonestreet, B. S.; McKinney, R. L.; Dysart, K. C.; Gien, J.; Baker, C. D.; Donohue, P. K.; Austin, E.; Fike, C.; Nelin, L. D., Interdisciplinary Care of Children with Severe Bronchopulmonary Dysplasia. J. Pediatr. 2017, 181, 12-28.

40. Nutrition, A. C. o., Pediatric Nutrition. Elk Grove Village, 2020.

41. Carver, J. D., Nutrition for preterm infants after hospital discharge. Adv. Pediatr. 2005, 52, 23-47.

42. Brunton, J. A.; Saigal, S.; Atkinson, S. A., Growth and body composition in infants with bronchopulmonary dysplasia up to 3 months corrected age: A randomized trial of a high-energy nutrient- enriched formula fed after hospital discharge. J. Pediatr. 1998, 133 (3), 340-345.

43. Forsyth, J.; Murdock, N.; Crighton, A., Low birthweight infants and total parenteral nutrition immediately after birth. III. Randomised study of energy substrate utilisation, nitrogen balance, and carbon dioxide production. Archives of Disease in Childhood-Fetal and Neonatal Edition 1995, 73 (1), F13-F16.

44. Pereira, G. R.; Baumgart, S.; Bennett, M. J.; Stallings, V. A.; Georgieff, M. K.; Hamosh, M.; Ellis, L., Use of high-fat formula for premature infants with bronchopulmonary dysplasia: metabolic, pulmonary, and nutritional studies. J. Pediatr. 1994, 124 (4), 605-11.

45. Shaikhkhalil, A. K.; Curtiss, J.; Puthoff, T. D.; Valentine, C. J., Enteral zinc supplementation and growth in extremely-low-birth-weight infants with chronic lung disease. J. Pediatr. Gastroenterol. Nutr. 2014, 58 (2), 185-189.

46. Guidelines for the Use of Parenteral and Enteral Nutrition in Adult and Pediatric Patients. JPEN 2002, 26: 1SA-138SA.

47. McGrath-Morrow, S. A.; Hayashi, M.; Aherrera, A. D.; Collaco, J. M., Respiratory outcomes of children with BPD and gastrostomy tubes during the first 2 years of life. Pediatr. Pulmonol. 2014, 49 (6), 537-543.

This article is protected by copyright. All rights reserved. 
48. Brun, G.; Fischer Fumeaux, C. J.; Giannoni, E.; Bickle Graz, M., Factors associated with postmenstrual age at full oral feeding in very preterm infants. PLoS One 2020, 15 (11), e0241769.

49. Mizuno, K.; Nishida, Y.; Taki, M.; Hibino, S.; Murase, M.; Sakurai, M.; Itabashi, K., Infants with bronchopulmonary dysplasia suckle with weak pressures to maintain breathing during feeding. Pediatrics 2007, 120 (4), e1035-e1042.

50. Wang, L. Y.; Luo, H. J.; Hsieh, W. S.; Hsu, C. H.; Hsu, H. C.; Chen, P. S.; Chiu, N. C.; Lee, W. T.; Jeng, S. F., Severity of bronchopulmonary dysplasia and increased risk of feeding desaturation and growth delay in very low birth weight preterm infants. Pediatr. Pulmonol. 2010, 45 (2), 165-73.

51. Warren, M. G.; Do, B.; Das, A.; Smith, P. B.; Adams-Chapman, I.; Jadcherla, S.; Jensen, E. A.; Goldstein, R. F.; Goldberg, R. N.; Cotten, C. M.; Bell, E. F.; Malcolm, W. F., Gastrostomy Tube Feeding in Extremely Low Birthweight Infants: Frequency, Associated Comorbidities, and Long-term Outcomes. J. Pediatr. 2019, 214, 41-41.

52. McSweeney, M. E.; Kerr, J.; Amirault, J.; Mitchell, P. D.; Larson, K.; Rosen, R., Oral feeding reduces hospitalizations compared with gastrostomy feeding in infants and children who aspirate. The Journal of pediatrics 2016, 170, 79-84.

53. Biniwale, M. A.; Ehrenkranz, R. A., The role of nutrition in the prevention and management of bronchopulmonary dysplasia. Semin. Perinatol. 2006, 30 (4), 200-208.

54. Lehtinen, A.; Korhonen, P.; Hyödynmaa, E.; Koivisto, A.; Peltola, T.; Hämäläinen, M.; Moilanen, E.; Tammela, O., Adipokines played a limited role in predicting temporary growth differences between very low birthweight infants with and without bronchopulmonary dysplasia. Acta Paediatr. 2017, 106 (10), 1583-1588.

55. Bott, L.; Béghin, L.; Hankard, R.; Pierrat, V.; Gondon, E.; Gottrand, F., Resting energy expenditure in children with neonatal chronic lung disease and obstruction of the airways. Br. J. Nutr. 2007, 98 (4), 796-801.

56. Davis, N. L.; Liu, A.; Rhein, L., Feeding immaturity in preterm neonates: Risk factors for oropharyngeal aspiration and timing of maturation. J. Pediatr. Gastroenterol. Nutr. 2013, 57 (6), 735-740.

57. Lefton-Greif, M. A.; McGrath-Morrow, S. A. In Deglutition and respiration: development, coordination, and practical implications, Semin. Speech Lang., Copyright(C) 2007 by Thieme Medical Publishers, Inc., 333 Seventh Avenue, New ...: 2007; pp 166179.

58. Brands, B.; Demmelmair, H.; Koletzko, B.; Project, E., How growth due to infant nutrition influences obesity and later disease risk. Acta Paediatr. 2014, 103 (6), 578-585.

This article is protected by copyright. All rights reserved. 
59. Lapillonne, A.; Griffin, I. J., Feeding preterm infants today for later metabolic and cardiovascular outcomes. The Journal of pediatrics 2013, 162 (3), S7-S16.

60. Lista, G.; Meneghin, F.; Bresesti, I.; Cavigioli, F., Nutritional problems of children with bronchopulmonary dysplasia after hospital discharge. Pediatr. Med. Chir. 2017, 39 (4), 183.

61. Arigliani, M.; Spinelli, A. M.; Liguoro, I.; Cogo, P., Nutrition and lung growth. Nutrients 2018, 10 (7), 919.

62. Allen, J.; Zwerdling, R.; Ehrenkranz, R.; Gaultier, C.; Geggel, R.; Greenough, A.; Kleinman, R.; Klijanowicz, A.; Martinez, F.; Ozdemir, A.; Panitch, H. B.; Nickerson, B.; Stein, M. T.; Tomezsko, J.; Van Der Anker, J.; American Thoracic, S., Statement on the care of the child with chronic lung disease of infancy and childhood. Am. J. Respir. Crit. Care Med. 2003, 168 (3), 356-96.

Table 1. NICU morbidities and other factors associated with a higher incidence of postnatal growth failure

Bronchopulmonary dysplasia

Necrotizing enterocolitis

Severe intracranial hemorrhage

Late-onset sepsis

Male gender

Need for assisted ventilation on the first day of life

Need for respiratory support at 28 days of age

Treatment with postnatal steroids

This article is protected by copyright. All rights reserved. 